\title{
过渡金属镍与可见光双催化体系的研究进展
}

\author{
阮利衡董振诚陈春欣吴爽* 孙京* \\ (辽宁石油化工大学 化学化工与环境学部 抚顺 113001)
}

\begin{abstract}
摘要 过渡金属镍与可见光催化剂的双催化体系，为构建新型的碳一碳键及碳一杂键提供了一种新的思路，实现了许多 单独催化体系难以完成的反应. 双催化体系具有条件温和、绿色清洁等优势, 引起了广大科研工作者的兴趣. 基于近些 年镍与可见光双催化反应进行了简要的概述.
\end{abstract}

关键词 可见光催化; 镍催化; 单电子转移; 能量转移

\section{Recent Progress on the Nickel/Photoredox Dual Catalysis}

\author{
Ruan, Liheng Dong, Zhencheng Chen, Chunxin Wu, Shuang* Sun, Jing* \\ (College of Chemistry, Chemical Engineering and Environmental Engineering, Liaoning Shihua University, Fushun 113001)
}

\begin{abstract}
A dual-catalysis system merging the visible light photoredox with transition metal nickel catalysis enables a new strategy to build the novel carbon-carbon and carbon-heteroatom bond, which are not generally possible via using either photoredox or nickel catalysis alone. This mild, green and promising protocol has attracted the interest of some scientific researchers. In this review, the recent progress of nickel/photoredox dual catalysis is summarized.

Keywords photocatalysis; nickel catalysis; single electron transfer; energy transfer
\end{abstract}

在 “绿色化学” 理念的推动下，寻找更加清洁、经 济、高效的能源一直是化学家努力的方向. 众所周知, 太阳能是自然界中最为丰富的能源, 其中, 地面接收太 阳辐射的 $43 \%$ 为可见光 ${ }^{[1]}$. 然而绝大多数有机分子不能 直接吸收可见光, 直至科研工作者们发掘了钌、铱金属 络合物以及有机染料的可见光催化性能, 许多反应在可 见光条件下才可以顺利地进行. 清洁绿色的可见光引发 的烷基化 ${ }^{[2]}$ 、芳基化 ${ }^{[3]}$ 、环加成 ${ }^{[4]}$ 及脱卤 ${ }^{[5]}$ 等反应得到了 广泛的研究和应用, 已成为有机光化学领域的研究热 点 ${ }^{[6 \sim 18]}$, 同时也让有机合成化学迎来了新的春天.

有机合成中 $\mathrm{C}\left(\mathrm{sp}^{2}\right)-\mathrm{C}\left(\mathrm{sp}^{2}\right)$ 键的构建目前已比较成 熟, 过渡金属催化的交叉偶联反应是最有效的方法, 传 统的交叉偶联反应, 经历氧化加成、金属交换与还原消 除三个关键步骤(Scheme 1). 在其他过程不断取得进展 的情况下, 偶联反应中的金属交换部分几乎没有明显进 展. 金属交换通常是该类反应的决速步骤, 不同杂化形 态碳的交换速率为 $\mathrm{C}(\mathrm{sp})>\mathrm{C}\left(\mathrm{sp}^{2}\right)>\mathrm{C}\left(\mathrm{sp}^{3}\right)^{[19]}$, 导致直接 构建 $\mathrm{C}\left(\mathrm{sp}^{3}\right)-\mathrm{C}\left(\mathrm{sp}^{2}\right)$ 或 $\mathrm{C}\left(\mathrm{sp}^{3}\right)-\mathrm{C}\left(\mathrm{sp}^{3}\right)$ 键十分困难. 相较
于传统钯催化下的转金属化过程, 可见光引发的单电子 转金属化使得 $\mathrm{C}\left(\mathrm{sp}^{3}\right)$ 容易发生交叉偶联反应. 研究表明: 可见光引发的单电子转金属化的速率为 $\mathrm{C}\left(\mathrm{sp}^{3}\right)>$ $\mathrm{C}\left(\mathrm{sp}^{2}\right)>\mathrm{C}(\mathrm{sp})$, 因此在可见光作用下, $\mathrm{C}\left(\mathrm{sp}^{3}\right)$ 更容易发生 交叉偶联反应 ${ }^{[19]}$. 若将可见光催化体系引入到传统的 过渡金属催化体系中便可以很好地解决 $\mathrm{C}\left(\mathrm{sp}^{3}\right)-\mathrm{C}\left(\mathrm{sp}^{2}\right)$ 或 $\mathrm{C}\left(\mathrm{sp}^{3}\right)-\mathrm{C}\left(\mathrm{sp}^{3}\right)$ 键不易构建的问题.

过渡金属钯、镍等在交叉偶联反应中都得到了广泛 的研究, 而过渡金属镍催化相较于钯催化更容易发生单 电子转移, 同时过渡金属镍也更廉价. 因此, 镍与可见 光的双催化体系引起了广泛的关注. 可见光催化体系通 常经历还原淬灭循环、氧化淬灭循环或能量转移(ET)历 程(Scheme 1), 其不仅具有非常良好的氧化还原性能, 还可以完成能量转移. 那么在双催化体系中, 可见光催 化既可以通过单电子还原或单电子氧化过程推动过渡 金属镍催化，又可以通过能量转移促进镍催化循环，过 渡金属镍和可见光起到协同催化作用.

具有清洁、绿色、高效等优势的镍与可见光双催化

\footnotetext{
* Corresponding authors. E-mail: wushuang05715@163.com, sunjing@lnpu.edu.cn Received April 30, 2017; revised June 5, 2017; published online June 16, 2017.

Project supported by the Fund of Liaoning Provincial Department of Education (No. L2016022), and the Talent Scientific Research Found of Liaoning Shihua University (No. 2016XJJ-006).

辽宁省教育厅一般项目基金(No. L2016022)及辽宁石油化工大学引进人才科研启动基金(No. 2016XJJ-006)资助项目.
} 

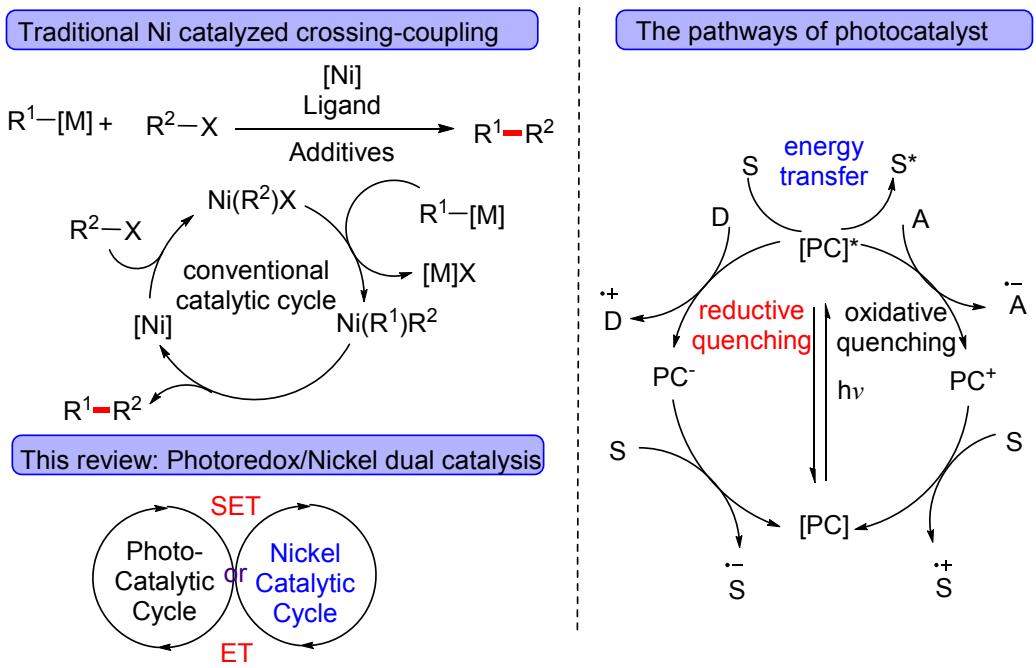

图式 1 传统镍催化、光催化及双催化体系

Scheme 1 Traditional nickel catalysis, photocatalysis and dual catalysis

体系, 实现了一些在单独催化体系中难以完成的反应过 程, 为有机合成中碳一碳键或碳一杂键的构建提供了一种 新的思路. 过渡金属与可见光双催化体系蓬勃发展, 近 年来, 侧重于作者课题组的工作 ${ }^{[20]}$ 及前期双催化体系 的总结见诸报端 ${ }^{[21]}$. 但是该领域发展异常迅猛, 最新的 研究结果不断地涌现, 极大地丰富了镍与可见光的双催 化体系. 因此, 本文主要依据可见光催化剂参与反应的 历程, 结合国内外最新的研究报道对镍与可见光双催化 反应进行了分类和归纳, 以期对该领域的发展起到一定 的积极作用.

\section{SET 交叉偶联反应}

\section{1 碳一碳键构建}

\subsection{1 脱羧偶联}

羧酸衍生物经由光氧化还原过程脱去二氧化碳后 可以得到烷基自由基, 是一类非常理想的自由基来源. 近年来, 一些科研工作者开展了基于镍与可见光双催化 体系下的羧酸及其衍生物与卤代烃的交叉偶联反应. 2014 年, MacMillan 课题组 ${ }^{[19]}$ 首次报道了可见光催化剂 铱络合物 4 和过渡金属镍催化剂共同催化的羧酸 1 与芳 基卤化物 2 直接构建新型 $\mathrm{C}\left(\mathrm{sp}^{3}\right)-\mathrm{C}\left(\mathrm{sp}^{2}\right)$ 的反应(Scheme 2). 铱络合物吸收可见光能量后到达激发态, 随后单电 子氧化羧酸 1 脱去 $\mathrm{CO}_{2}$ 生成烷基自由基物种 $\mathbf{5}$, 与此同 时芳基卤化物 2 与 $\mathrm{Ni}(0)$ 氧化加成得到 $\mathrm{Ni}(\mathrm{II})$ 中间体, $\mathrm{Ni}(\mathrm{II})$ 中间体迅速捕捉体系中的烷基自由基 $\mathbf{5}$ 得到 $\mathrm{Ni}(\mathrm{III})$ 加合物, 之后还原消除得到目标产物 3 和 $\mathrm{Ni}(\mathrm{I})$, 最后单电子还原 $\mathrm{Ni}(\mathrm{I})$ 至 $\mathrm{Ni}(0)$ 完成整个催化循环. 同年, 他们 ${ }^{[22]}$ 报道了单独可见光催化体系 Boc- $L$-脯氨酸与对 苯二腈的脱羧偶联反应, 两种底物在可见光催化体系经
历两次单电子转移(SET)得到两种自由基物种, 随后发 生自由基之间的偶联. 双催化体系同样经历两次单电子 转移，但一次形成烷基自由基，另一次则作用于金属镍 络合物. 由此可见, 通过单电子转移成功地实现了可见 光催化与过渡金属镍催化的有机结合, 拓展了过渡金属 催化和光催化的应用范围.

随后, MacMillan 课题组 ${ }^{[23]}$ 报道了在温和条件下简 单丰富的羧酸化合物 6 和烷基卤化物 7 的偶联反应 (Scheme 3). 作者成功地将亲电试剂由芳基卤化物拓宽 到烷基溴化物, 为构建 $\mathrm{C}\left(\mathrm{sp}^{3}\right)-\mathrm{C}\left(\mathrm{sp}^{3}\right)$ 键提供了一种新 的方法. 同时, 通过镍与可见光双催化体系可以直接方 便地制备医药化合物 $\mathbf{1 0}$.

在 2016 年, Fu 课题组与 MacMillan 课题组 ${ }^{[24]}$ 开展 合作成功地将镍与可见光双催化体系应用到非对称合 成中, 丰富了光催化手性合成方法学(Scheme 4). 从自 然界普遍存在的氨基酸 11 和芳(杂)环卤化物 12 出发, 合成了一系列具有高对映选择性的苄基胺化合物 13, 并进一步合成了一些具有生物活性的化合物.

MacMillan 课题组在双催化体系下又相继报道了原

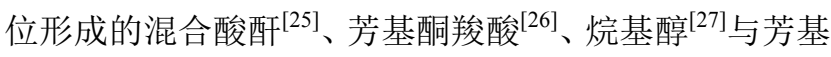
卤代烃的脱羒偶联反应; 期间, $\mathrm{Gu}$ 等 ${ }^{[28]}$ 报道了 $\alpha$-羰基羧 酸与吲哚的脱羧偶联反应; Oderinde 等 ${ }^{[29]}$ 详细阐述了镍 与可见光双催化体系中分子氧、溶剂及光源对交叉偶联 反应的影响; Tong 小组 ${ }^{[30]}$ 则报道了在镍、锌及可见光催 化剂三重作用下的 $\alpha$-羟基酸- $O$-羧内酸酝脱除 $\mathrm{CO}_{2}$ 的可 控开环聚合反应.

Zhang 课题组 ${ }^{[31]}$ 合成了一系列供体-受体荧光化合 物, 为非金属光催化剂的设计提供了理论支持, 其中 2,4,5,6-四(9-咔唑基)-间苯二腈(4CzIPN)展现出高效的 光催化活性, 可以用来替代昂贵的钉、铱光催化剂 

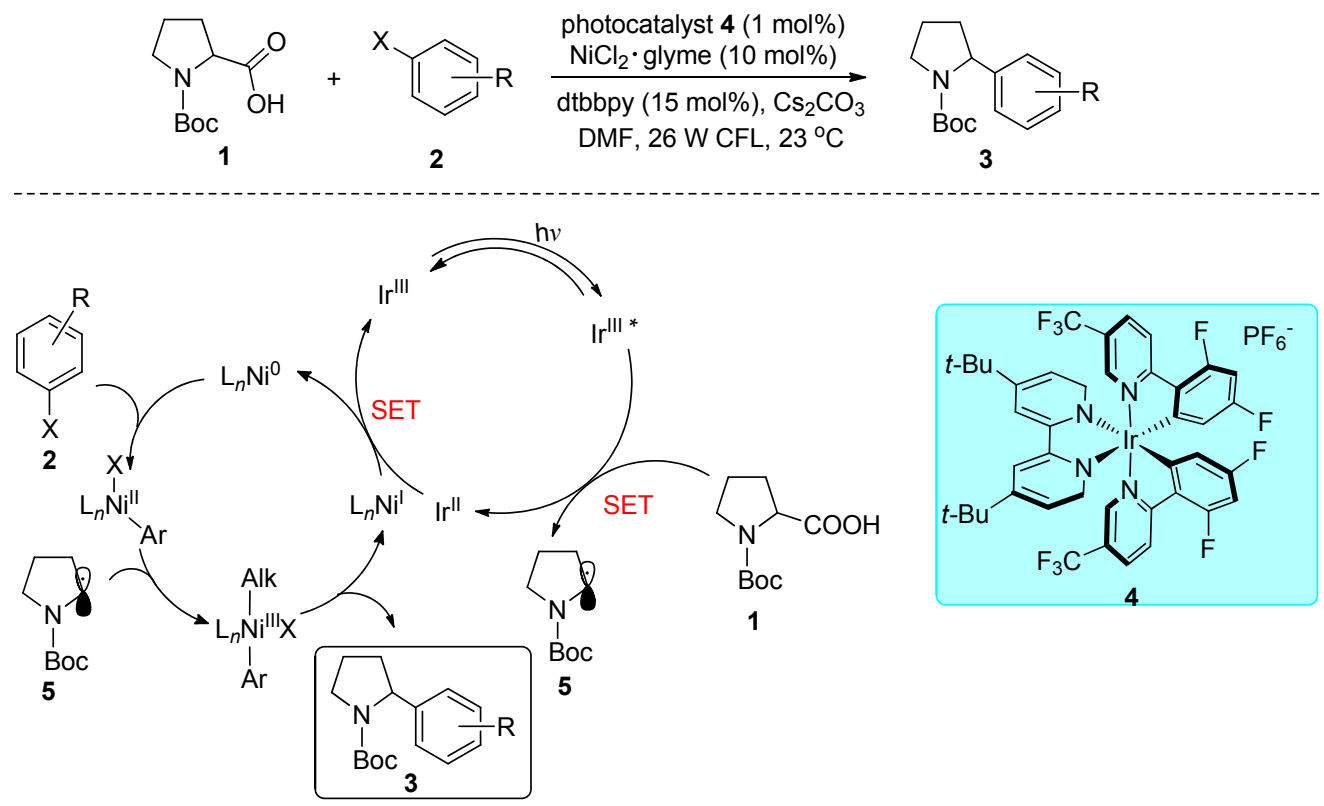

图式 $2 \mathrm{C}\left(\mathrm{sp}^{3}\right)-\mathrm{C}\left(\mathrm{sp}^{2}\right)$ 键的构建

Scheme 2 Formation of $\mathrm{C}\left(\mathrm{sp}^{3}\right)-\mathrm{C}\left(\mathrm{sp}^{2}\right)$ bond

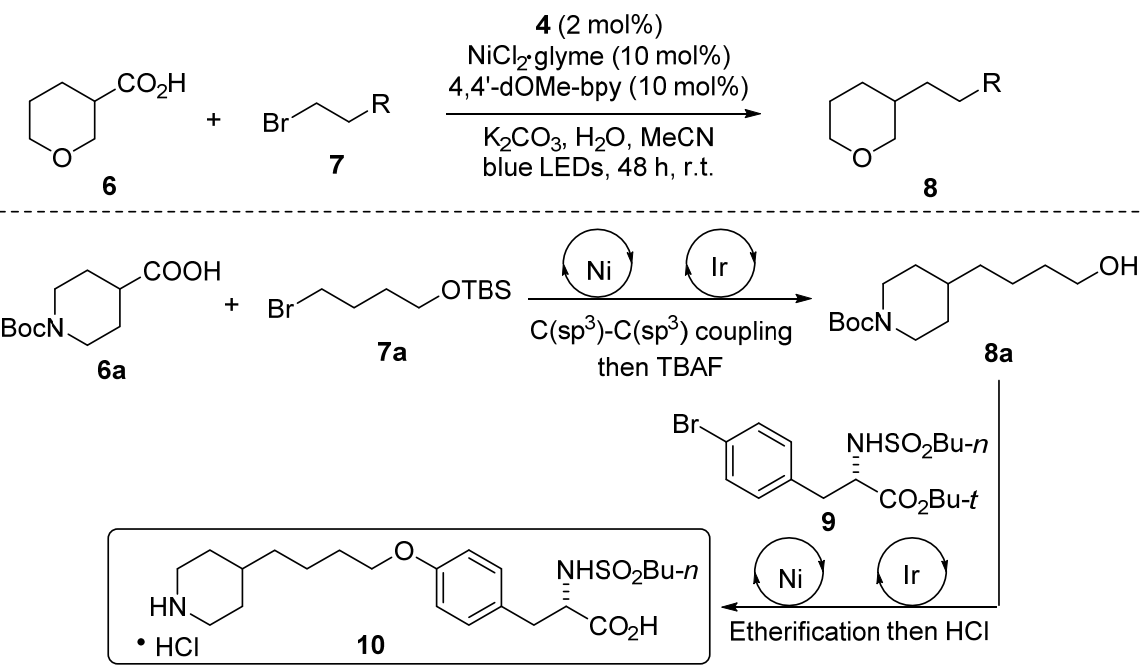

图式 $3 \mathrm{C}\left(\mathrm{sp}^{3}\right)-\mathrm{C}\left(\mathrm{sp}^{3}\right)$ 键的构建

Scheme 3 Formation of $\mathrm{C}\left(\mathrm{sp}^{3}\right)-\mathrm{C}\left(\mathrm{sp}^{3}\right)$ bond

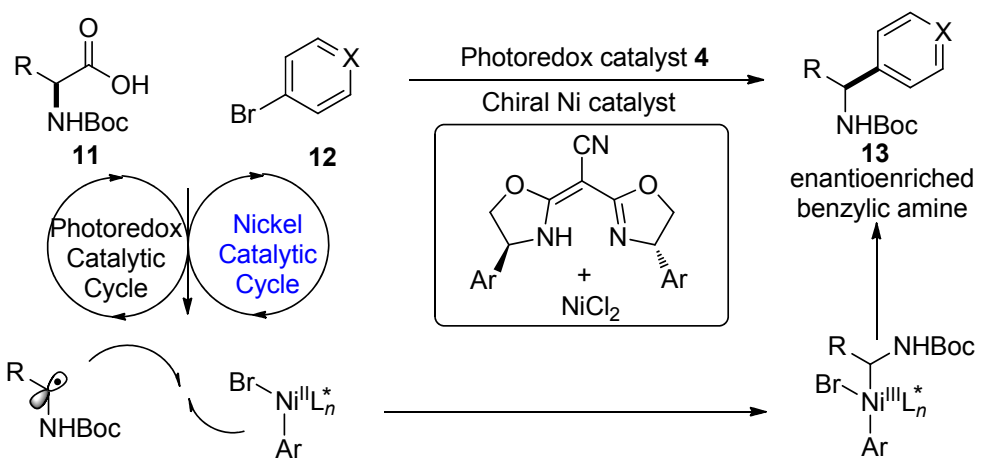

图式 4 手性苄胺的合成

Scheme 4 Preparation of chiral benzylic amines 
(Scheme 5); Mariano 等 ${ }^{[32]}$ 研究了有机光催化剂 4CzIPN 与过渡金属镍催化剂组成的双催化体系催化下的新型 甲酰化策略.
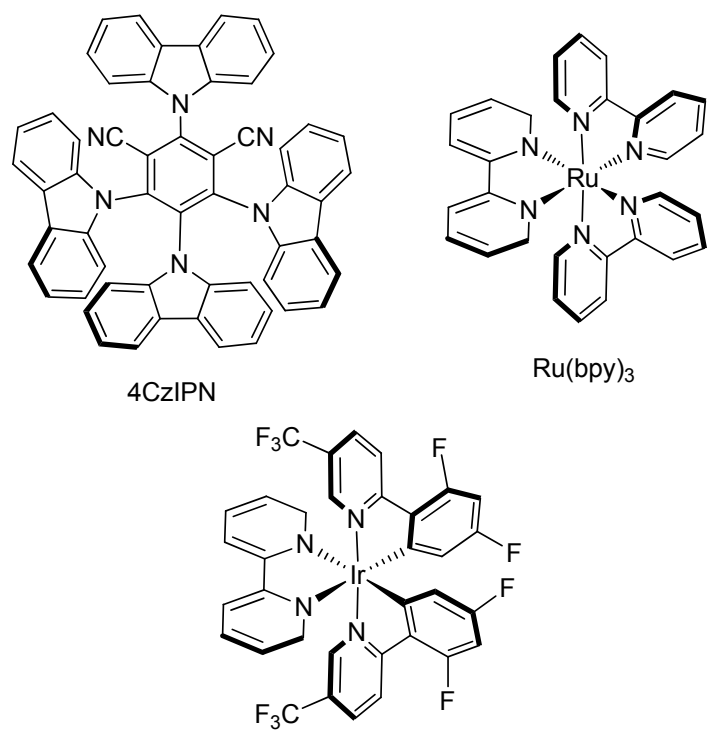

$\operatorname{Ir}\left[\mathrm{dF}\left(\mathrm{CF}_{3}\right) \mathrm{ppy}\right]_{2}$ (bpy)

图式 5 可见光催化剂的结构

Scheme 5 Structures of photocatalyst

2017 年, Scaiano 课题组 ${ }^{[33]}$ 在非均相催化体系下成 功地实现了羧酸 1 与芳基碘化物 14 的交叉偶联反应(Eq. 1). 该双催化体系由 $\mathrm{TiO}_{2}$ 和二甲氧基乙烷氯化镍组成, $\mathrm{TiO}_{2}$ 在重复使用五次之后反应效率仅有稍微的下降, 然 而底物的范围受到一定的限制. 但是, $\mathrm{TiO}_{2}$ 廉价丰富及 可回收性的特性足以引起更多科研工作者的兴趣, 而且 非均相催化进一步拓宽了双催化体系的应用范围.

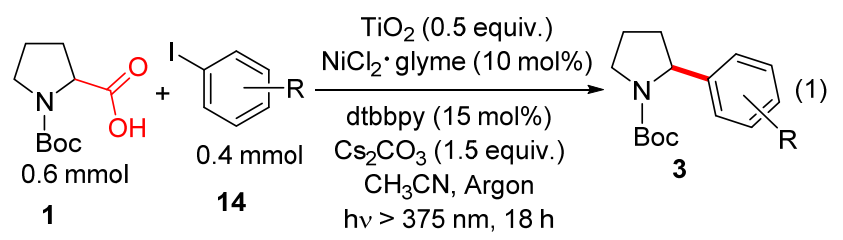

\subsection{2 有机硼烷偶联}

相比较于硼酸或硼酸酯, 有机三氟硼酸盐更加稳定 且具有较低的氧化电势, 在交叉偶联反应中是非常良好 的 $\mathrm{C}\left(\mathrm{sp}^{3}\right)$ 型亲核试剂. 2014 年, Molander 等 ${ }^{[34]}$ 报道了过 渡金属镍与可见光双催化体系下有机三氟嗍酸盐 15 与 溴苯 16 的交叉偶联反应(Eq. 2). 与传统有机硼试剂在偶 联反应中的双电子转金属化不同, 该反应体系中有机三 氟嗍酸盐经历了单电子转金属化.

2015 年, Molander 课题组 ${ }^{[35]}$ 首次报道了 $\alpha$-氨基甲基 三氟硼酸盐 18 在可见光铱催化剂及过渡金属镍催化剂 协同作用下合成手性氨基酸衍生物的偶联反应(Eq. 3).
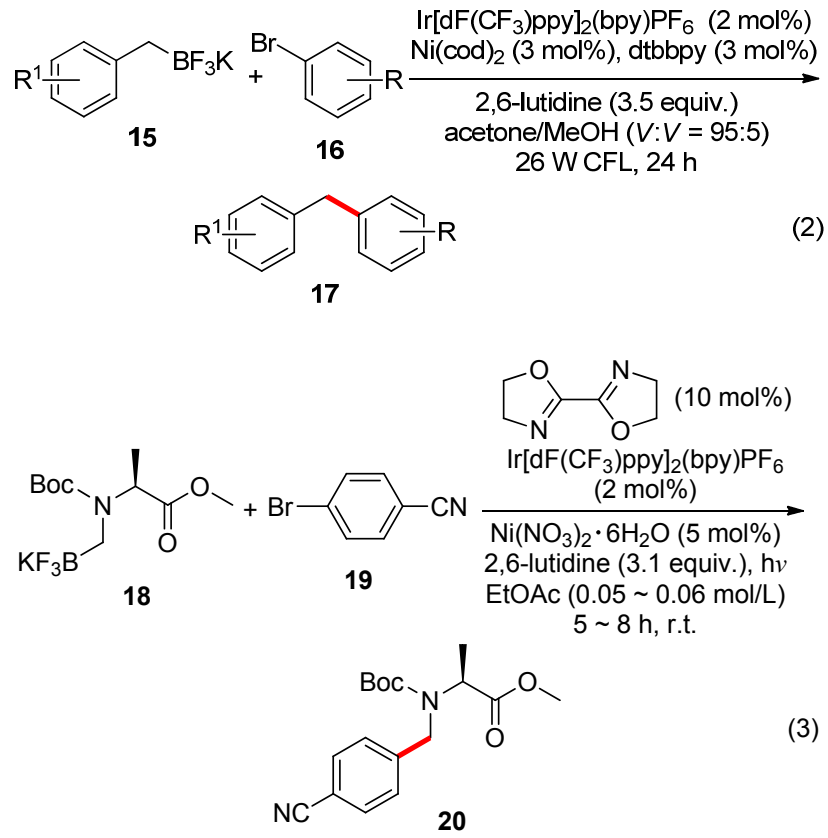

手性的天然氨基酸引入了三氟嗍酸盐基团后, 其在可见 光条件下经历单电子转移后得到了烷基自由基物种, $\mathrm{Ni}$ 经由氧化、还原等过程最终构建了新的 $\mathrm{C}\left(\mathrm{sp}^{3}\right)-\mathrm{C}\left(\mathrm{sp}^{2}\right)$ 键得到了手性氨基酸衍生物 $\mathbf{2 0}$.

随后, Kozlowski 与 Molander 等 ${ }^{[36]}$ 展开合作通过泛 函密度理论(DFT)深入研究了烷基三氟硼酸盐与芳基溴 化物在双催化体系下的反应机理. 各种取代的三氟硼酸 盐通过可见光催化可以得到相应的烷基自由基物种 21, 22, 23 (Scheme 6) ${ }^{[37]}$, 而这些烷基自由基又可以与各类 亲电试剂(卤代烃 ${ }^{[38,39]}$ 、硼化芳基卤代烃 ${ }^{[40]}$ 、酰氯 ${ }^{[41]}$ 及 氮(-酰基琥珀酰亚胺 ${ }^{[2]}$ ) 发生交叉偶联反应.

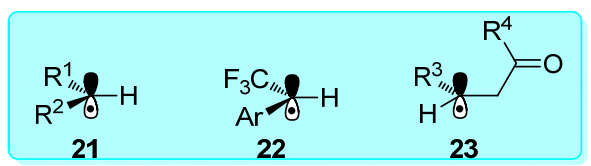

图式 6 碳自由基

Scheme 6 Carbon radical

三氟嗍酸盐的 $\alpha$ 位引入 $\mathrm{N}$ 原子使得 $\mathrm{C}-\mathrm{B}$ 键更易于 发生单电子转移而断裂. 在此思路基础上, 硼酸盐的 $\alpha$ 位引入 $\mathrm{O}$ 原子, 在双催化体系下反应同样可以顺利地进

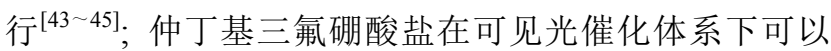
快速形成仲丁基，仲丁基起到活化黄原酸酯的作用，从 而实现双催化体系下黄原酸酯与澳苯的交叉偶联反 应 ${ }^{[46]}$; Doyle 等 ${ }^{[47]}$ 则研究了双催化体系下苠基三氟硼酸 盐与环状内消旋酸䣶的去对称化, 高效地合成具有高立 体对映选择性的酮酸化合物.

\subsection{3 有机硅烷偶联}

有机硅烷氧化电势很高, 通常在可见光条件下难以 
发生碳一硅键断裂，高价的酚硅化合物具有高稳定性、可 溶性、无害性及环境友好性, 同时其氧化还原电势较低 $\left(E^{\mathrm{o}}=0.3 \sim 0.9 \mathrm{~V}\right)$, 在可见光催化剂作用下可以得到烷基 自由基物种. 在 2015 年, Fensterbank 课题组 ${ }^{[48]}$ 成功地实 现了在双催化作用下高价酚硅 $\mathbf{2 4}$ 与对溴苯甲腈 $\mathbf{1 9}$ 的交 叉偶联反应(Eq. 4). 研究表明: 在可见光催化剂作用下 高价酚硅化合物可以高效地产生烷基自由基, 并且能够 顺利地完成进一步镍催化循环过程.

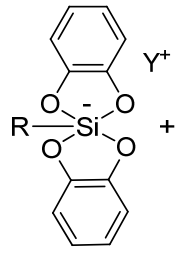<smiles>N#Cc1ccc(Br)cc1</smiles>

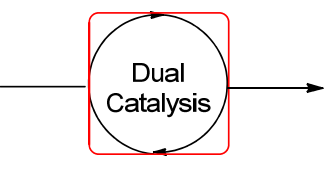

24<smiles>[R]c1ccc(C#N)cc1</smiles>

25
之后不久, Molander 课题组极大地拓宽了高价酚硅
化合物在双催化模型下的应用范围. 作者首先制备了一 系列稳定的高价酚硅化合物，在 $\left[\mathrm{NiCl}_{2}(\mathrm{dme})\right]$ (5 mol\%) 为催化剂, dtbbpy (5 mol\%)为配体, $\left[\mathrm{Ru}(\mathrm{bpy})_{3}\right]\left(\mathrm{PF}_{6}\right)_{2}(2$ $\mathrm{mol} \%$ ) 为可见光催化剂的条件下实现了高价酚硅与芳 (杂)环溴代烃的偶联反应 ${ }^{[49]}$ (Scheme 7). 接下来的研究 中, 偶联试剂由芳(杂)环溴代烃扩展到了烯基卤代 烃 ${ }^{[50]}$ 、烷基溴代烃 ${ }^{[51]} 、 2,1$-嗍氮杂䒺溴化物 ${ }^{[52]}$ 以及苯酚 衍生物(三氟甲磺酸酯、甲苯磺酸酯、甲磺酸酯) ${ }^{[53]}$; 高 价酚硅与嗍化芳基溴化物在有机光催化剂 4CzIPN 与过 渡金属镍双催化体系下依然可以高效地合成一系列烷 基取代的芳(杂)环硼化物 ${ }^{[54]}$; 高价酚硅在可见光催化体 系下得到的烷基自由基，同时是一种良好的氢原子转移 试剂，实现了芳(杂)环溴化物与硫醇的硫醚化反应 ${ }^{[55]}$ (Scheme 7).

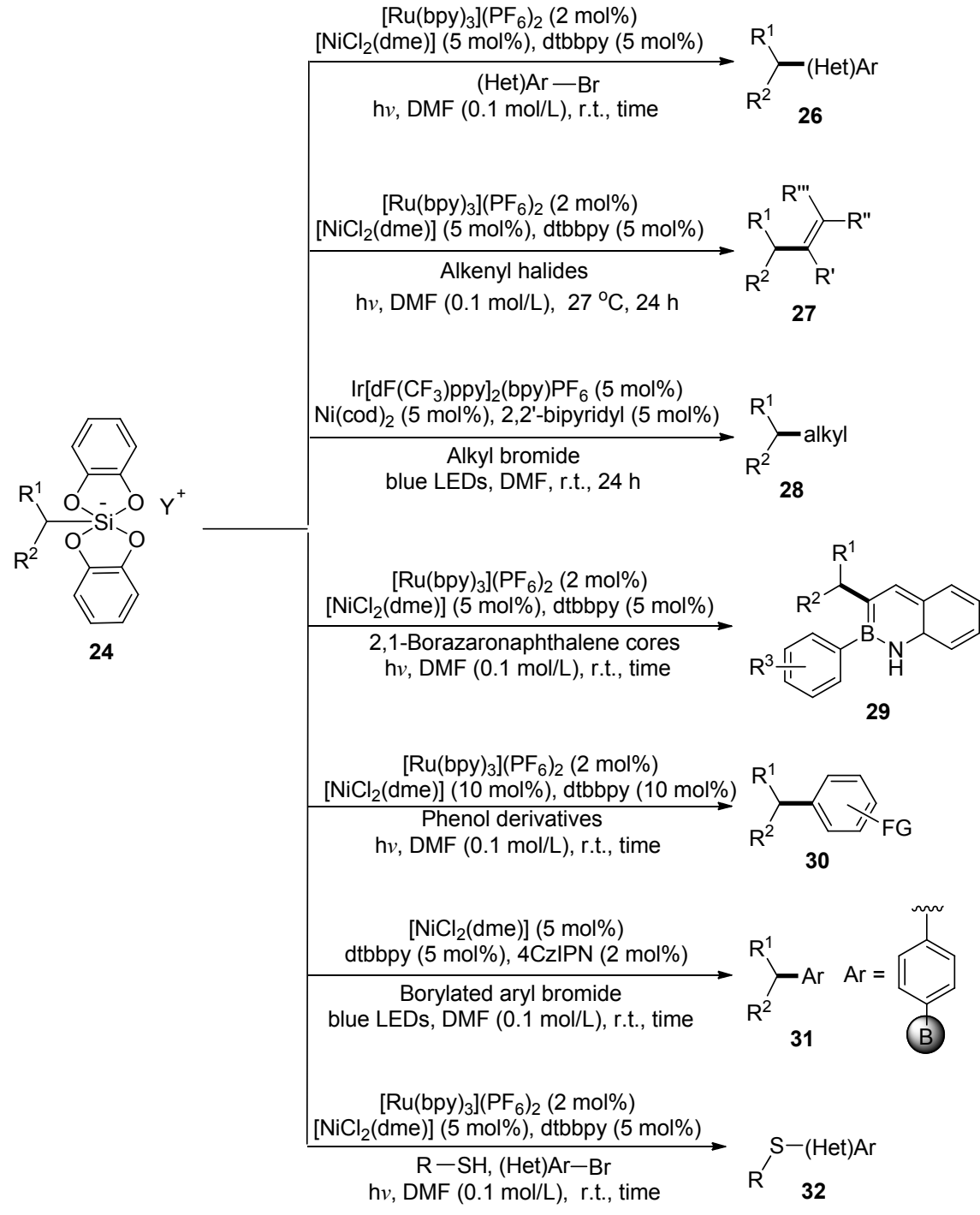

图式 7 高价酚硅作为自由基试剂

Scheme 7 Hypervalent silicates as radical agents 


\subsection{4 其它官能团化衍生物偶联}

1,4-二氢吡啶衍生物可以通过 “一步法” 从醛制备 而来, 亦是一类非常理想的烷基自由基来源. Molander 课题组 ${ }^{[56]}$ 报道了在过渡金属镍/有机光催化剂体系下的 1,4-二氢吡啶衍生物 33 和芳(杂)环溴化物的偶联反应 (Scheme 8), 该反应体系具有操作方便、条件温和、环 境友好及良好化学选择性等特点.

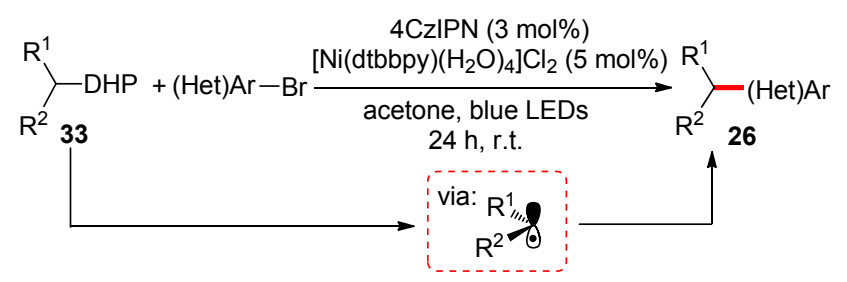<smiles>CCOC(=O)C1=C(C)NC(C)=C(C(=O)OCC)[C]1F</smiles>

图式 8 1,4-二氢吡啶类化合物作为自由基前体

Scheme 8 1,4-Dihydropyridines as radical precursors

烷基溴化物同样是比较理想的碳自由基来源, 武汉 大学雷爱文教授课题组 ${ }^{[57]}$ 研究了烷基溴化物与芳(杂)环
溴化物在双催化体系下直接构建 $\mathrm{C}\left(\mathrm{sp}^{3}\right)-\mathrm{C}\left(\mathrm{sp}^{2}\right)$ 键的反 应(Eq. 5). 反应体系不需要化学计量的锰或者锌作还原 剂, 而是使用常用的三乙胺作为最终的还原试剂. 2017 年, Vannucci 课题组 ${ }^{[58]}$ 开展了相类似的烷基溴化物与芳 基卤代烃的还原交叉偶联反应，底物具有非常好的普适 性，并提出了与雷爱文教授提出的反应机理相一致的反 应机理

\section{1 .5 碳氢化合物偶联}

碳氢化合物是自然界中最为常见的化合物，若是在 可见光作用下通过碳氢键活化得到烷基自由基，将极大 地丰富双催化模型的应用范围. 2016 年, Doyle 课题组 ${ }^{[59]}$ 报道了双催化体系下芳基胺 35 的 $\mathrm{sp}^{3}$ 碳一氢键酰基化反 应(Eq. 6). 温和条件下 $\mathrm{sp}^{3}$ 碳-氢键的直接活化可减少预 先官能团化等步骤，是一种环境友好的合成策略. 紧接 着，该课题组 ${ }^{[60]}$ 报道了芳基氯代烃与醚的 $\mathrm{C}\left(\mathrm{sp}^{3}\right)-\mathrm{H}$ 键 直接交叉偶联反应，该双催化体系烷基自由基来源不是 可见光直接单电子氧化底物得到的，而是首先芳基氯代 烃与 $\mathrm{Ni}(0)$ 氧化加成, 再经单电子氧化得到 $\mathrm{Ni}(\mathrm{III})$ 物种, 而 $\mathrm{Ni}(\mathrm{III})$ 物种在可见光的作用下形成氯自由基，最后氯 自由基篗取醚 $\alpha$ 位的氢原子得到烷基自由基.
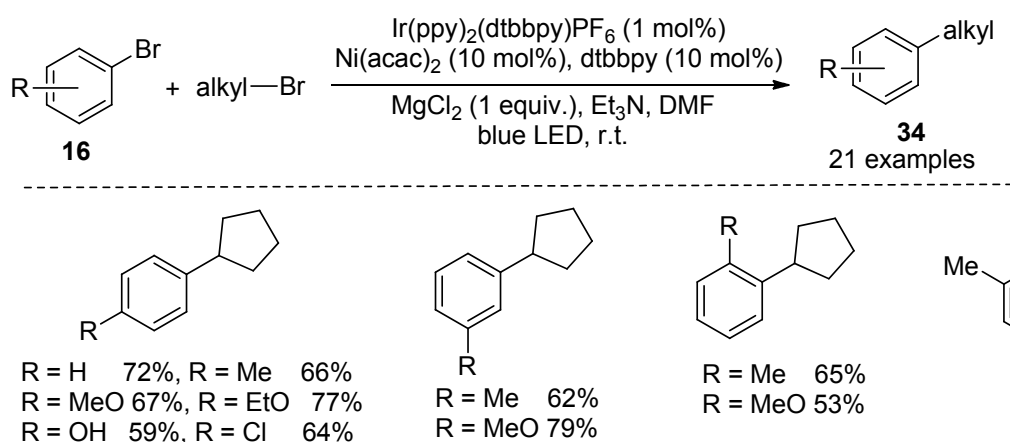<smiles>Cc1cc(C2CCCC2)cc([N+](=O)[O-])c1</smiles><smiles>CCC(c1ccccc1)c1ccccc1</smiles><smiles>COc1ccc2cc(C3CCCC3)ccc2c1</smiles><smiles>c1cc2c(cc1C1CCCC1)OCO2</smiles><smiles>c1cncc(C2CCCC2)c1</smiles><smiles>CC(C)c1ccccc1</smiles><smiles>CCOC(=O)CCCc1ccccc1</smiles><smiles>CCc1ccccc1</smiles>

$61 \%$

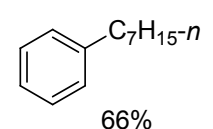

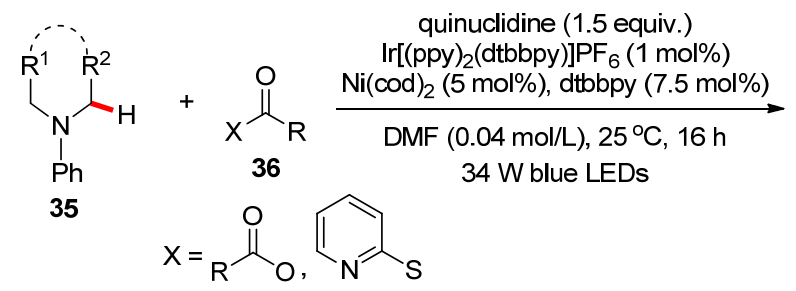<smiles>[R]CN([Pb])C([R])C([R])=O</smiles> 
2016 年, MacMillan 课题组 ${ }^{[61]}$ 利用溴化镍水合物作 为过渡金属催化剂, 铱络合物 4 作为光催化剂, 乙酰克 里定(3-acetoxyquinuclidine) 作为氢原子转移试剂, 在温 和条件下实现了 $\mathrm{C}\left(\mathrm{sp}^{3}\right)-\mathrm{H}$ 亲核试剂 38 与芳基卤代烃 16 的交叉偶联反应. 值得注意的是乙酰克里定在反应 体系中不仅仅是氢原子转移催化剂, 还要起到有机碱的 作用, 所以需要使用过量的乙酰克里定(1.1 equiv.). 作 者在可见光/镍双催化体系的基础上成功地引入了氢原 子转移试剂, 巧妙地实现了镍催化、可见光催化及有机 催化的结合(Eq. 7).

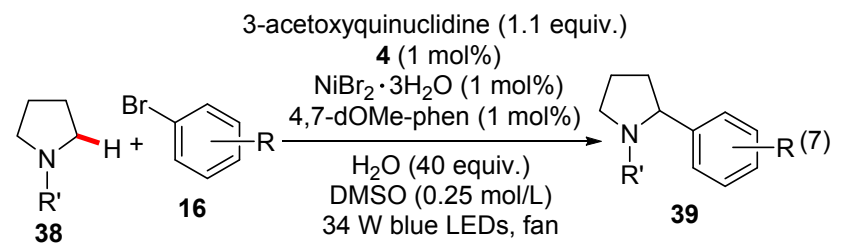

2017 年, 余达刚课题组 ${ }^{[62]}$ 报道了胺或醚 40 的 $\mathrm{C}\left(\mathrm{sp}^{3}\right)-\mathrm{H}$ 与 $\mathrm{C}\left(\mathrm{sp}^{2}\right)-\mathrm{O}$ 型亲电试剂 41 的直接烯基化和 芳(杂)化反应(Eq. 8). 该反应体系具有条件温和、官能团 容忍性好、底物适用范围广及选择性优良等特点, 极大 地扩展了双催化体系的应用范围.

\section{2 碳-杂键构建}

杂原子化合物在自然界中普遍存在, 是一类具有重 要生物活性的化合物. 在有机分子引入杂原子 $(\mathrm{O}, \mathrm{S}, \mathrm{N}$, $\mathrm{P}$ )往往能够改变整个分子的物理和化学性质, 因此构建 新型碳-杂键是非常重要的研究课题. 在双催化体系

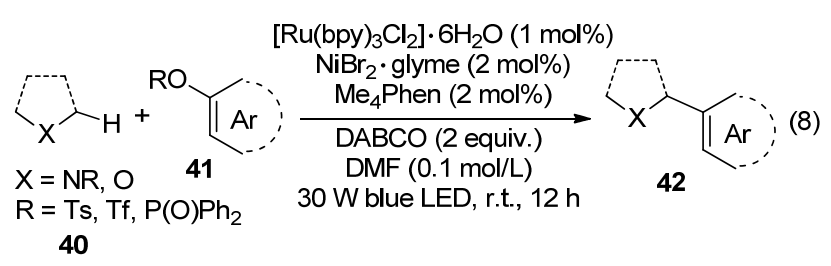

下构建碳一杂键的反应也引起了科研工作者的关注.

\subsection{1 自由基氧化镍物种}

可见光氧化还原体系通过羧酸、硼烷、硅烷等可以 得到烷基自由基，而在相似条件下硫醇能够形成相应的

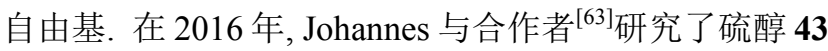
与芳基卤代烃 14 的偶联反应, 在可见光氧化还原作用 下硫醇可以得到颈基自由基(Scheme 9). 反应体系展现 出优秀的官能团容忍性，无论是芳基、芐基还是烷基硫 醇都能高效地与芳(杂)环碘化物发生交叉偶联反应. 机 理研究表明该反应与之前镍催化过程不同，该催化循环 不涉及 $\mathrm{Ni}(0)$, 而是通过瞬态的 $\mathrm{Ni}(\mathrm{I})$ 物种活化整个过程. 首先可见光催化体系单电子氧化硫醇 $\mathbf{4 3}$, 并在吡啶的 作用下脱去质子得到疏基自由基，单电子还原 45 生成 46. 与此同时, 46 迅速捕获颈基自由基形成 47, 随后 47 经由单电子还原得到 48 , 接着发生氧化加成、还原消除 得到目标偶联化合物 44 .

2015 年, 肖文精课题组 ${ }^{[64]}$ 工妙地利用镍与可见光 双催化模型在温和条件下高效地合成了一系列三芳基 膦氧化合物 (Eq. 9). 二芳基膦氧化合物 $\mathbf{5 0}$ 在可见光催化 循环中得到了以磷为中心的自由基物种, 继而参与镍催 化循环，最终得到目标化合物 $\mathbf{5 1}$.

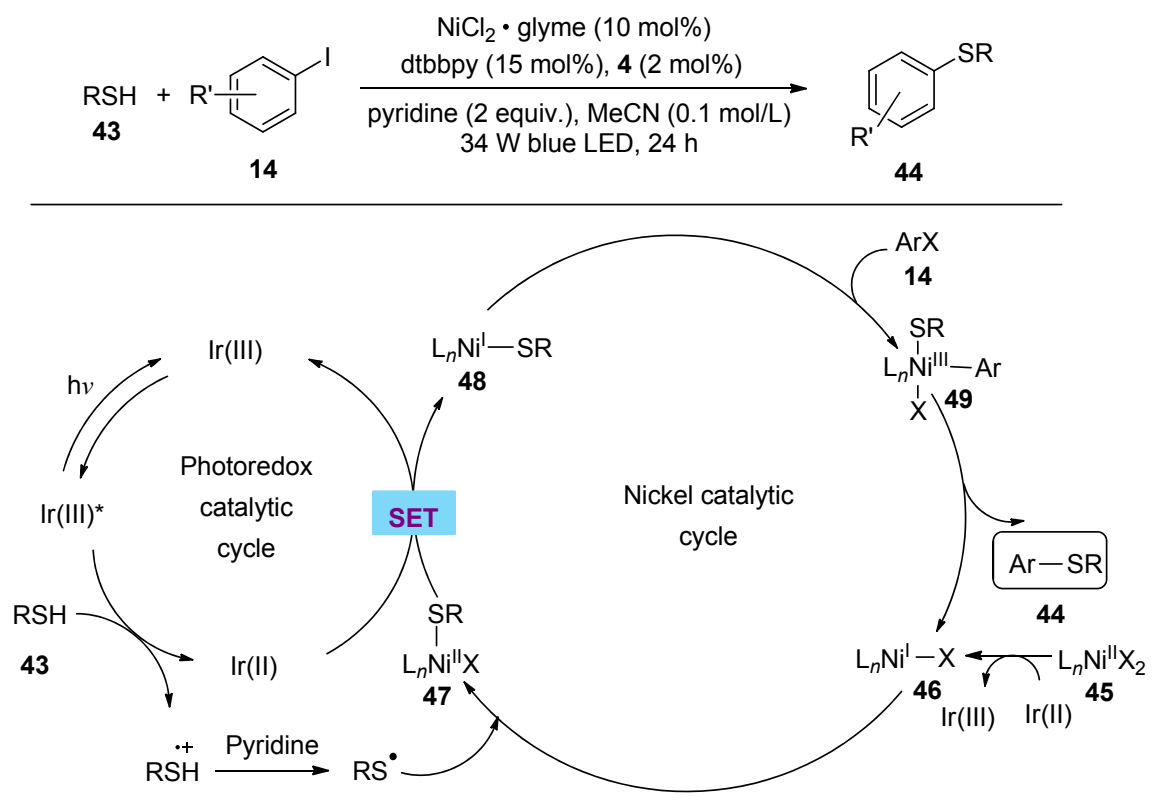

图式 9 碳一硫键的形成

Scheme 9 Bond building of $\mathrm{C}-\mathrm{S}$ 

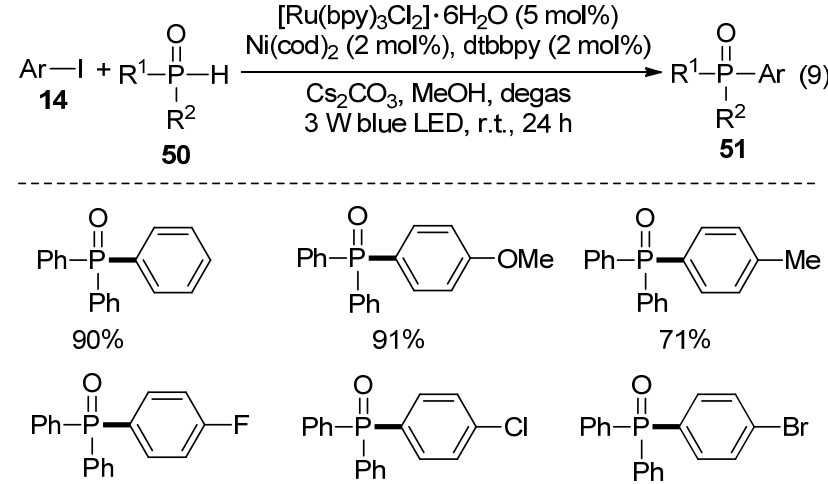

$81 \%$
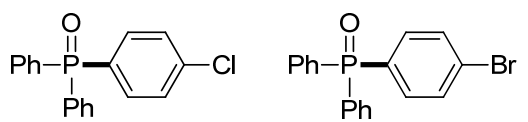

$88 \%$

$81 \%$<smiles>O=P(c1ccccc1)(c1ccccc1)c1cccc(O)c1</smiles><smiles>Nc1cccc(P(=O)(c2ccccc2)c2ccccc2)c1</smiles>

$85 \%$<smiles>CC(C)(C)Nc1cccc(P(=O)(c2ccccc2)c2ccccc2)c1</smiles>

$81 \%$

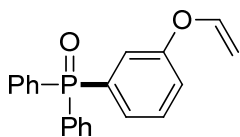

$83 \%$<smiles>Cc1ccc(P(=O)(c2ccccc2)c2ccc(C)cc2)cc1</smiles>

$69 \%$

\subsection{2 光催化直接氧化镍物种}

光氧化还原循环不仅可以通过单电子转移得到自 由基, 也可以直接单电子氧化还原镍物种, 实现整个双 催化循环. 2015 年, MacMillan 等 ${ }^{[65]}$ 报道了醇 $\mathbf{5 2}$ 与卤代 烃 16 在双催化体系下的交叉偶联反应(Scheme 10). 该 体系中瞬态的 $\mathrm{Ni}(\mathrm{III})$ 物种是由光催化循环直接单电子氧 化 $\mathrm{Ni}(\mathrm{II})$ 物种得到的, 这与自由基氧化镍物种的反应历 程不同. 同期, Jamison 课题组 ${ }^{[66]}$ 也研究了双催化体系下 具有相似催化历程的吲哚啉衍生物的高区域选择性合 成.

2016 年, Buchwald 课题组和 MacMaillan 课题组 ${ }^{[67]}$ 报道了无配体参与的镍盐与可见光共同催化的芳胺化 反应(Eq. 10). 该反应条件温和, 底物适应性好, 为含有 胺类结构单元的医药化合物、天然产物及精细化学品的 合成提供了新的方法，也是对传统过渡金属钯催化的芳 胺化反应的有益补充.

\section{ET 交叉偶联反应}

可见光催化循环不仅能够实现单电子转移, 还能发 生能量转移过程. 可见光催化剂吸收可见光的能量后可 以传递给其它有机分子促进反应的进行.
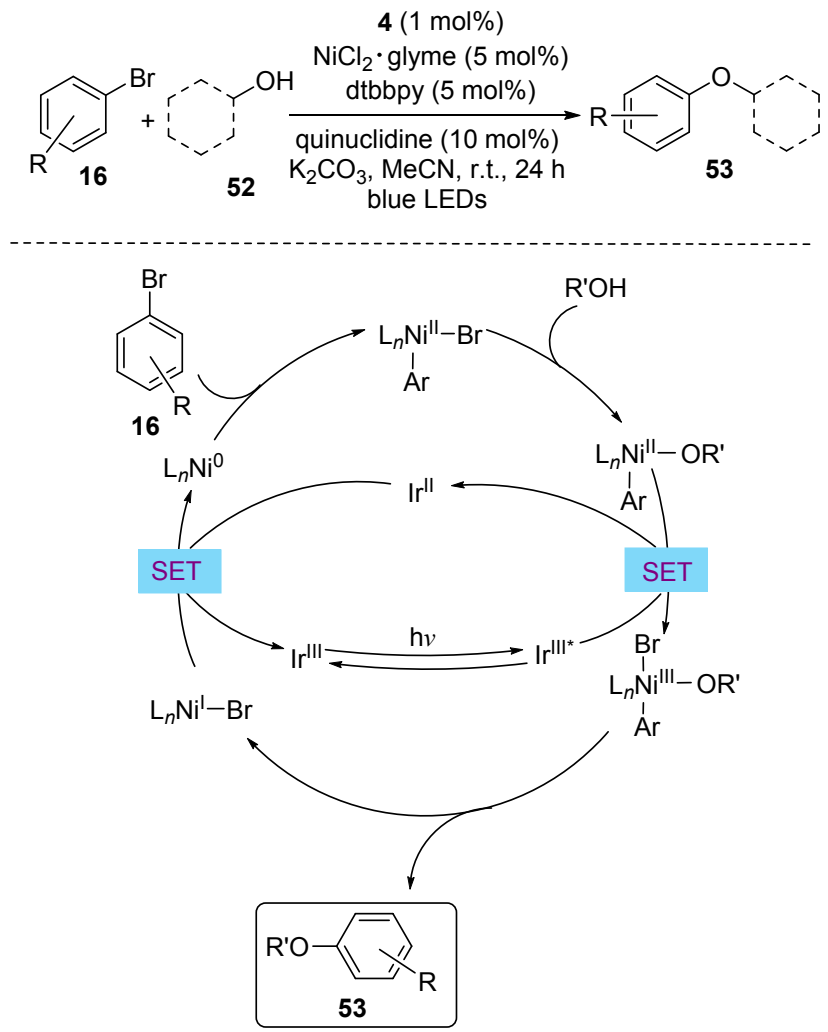

图式 10 碳一氧键的构建

Scheme 10 Construction of $\mathrm{C}-\mathrm{O}$ bond

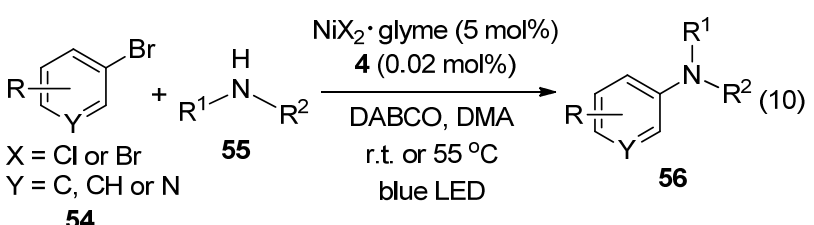

在 2016 年, Molander 课题组 ${ }^{[68}$ 报道了镍与可见光 双催化体系下通过能量转移方式的碳一氢键芳基化反应, 并对反应机理过程进行了深入的研究(Scheme 11). 动力 学研究表明: $\mathrm{Ni}-\mathrm{Br}$ 键的均裂形成溴自由基, 溴自由基 与底物之间发生氢原子转移得到了稳定的碳自由基. 镍 络合物 60 *到 61 有两种可能的途径: (A)离散的 $\mathrm{Ni}(\mathrm{I})$ 和 溴自由基; (B)协同形成的四中心过渡态.

传统过渡金属催化循环一般依赖于基态有机金属 配合物的氧化. 2017 年, MeCusker 课题组和 MacMillan 课题组 ${ }^{[69]}$ 研究了镍与可见光双催化体系下羧酸 $\mathbf{6 3}$ 与芳 基溴化物 16 的偶联反应，金属镍络合物在吸收光能量 后生成激发态的金属镍络合物从而促进反应的进行 (Scheme 12). 反应机理为: 对溴苯甲酸甲酯 $\mathbf{1 6}$ 与 $\mathrm{Ni}(0)$ 发生氧化加成得到 $\mathrm{Ni}(\mathrm{II})$ 物种 $\mathbf{6 5}$, 其经过配体的快速交 换生成新的 $\mathrm{Ni}$ (II)物种 $\mathbf{6 6}$, 同时铱催化剂吸收能量后到 达激发态, 66 通过能量转移形成激发态 $66^{*}$, 最后 $66^{*}$ 发 生还原消除得到目标偶联化合物 64 和 $\mathrm{Ni}(0)$, 从而完成 

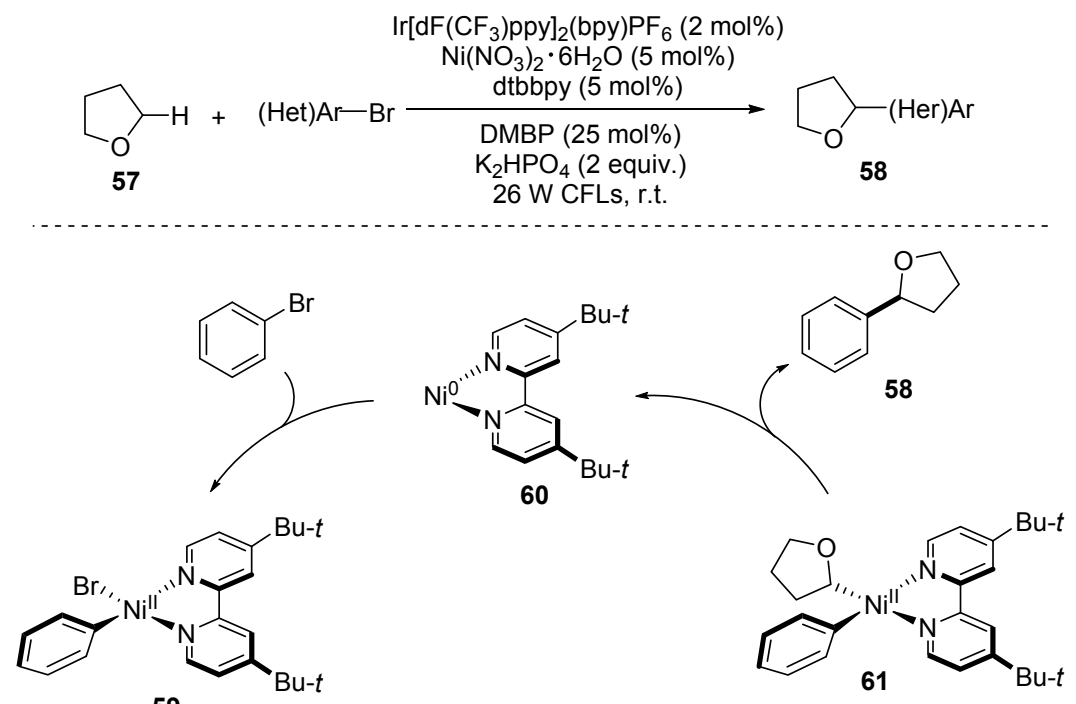

59
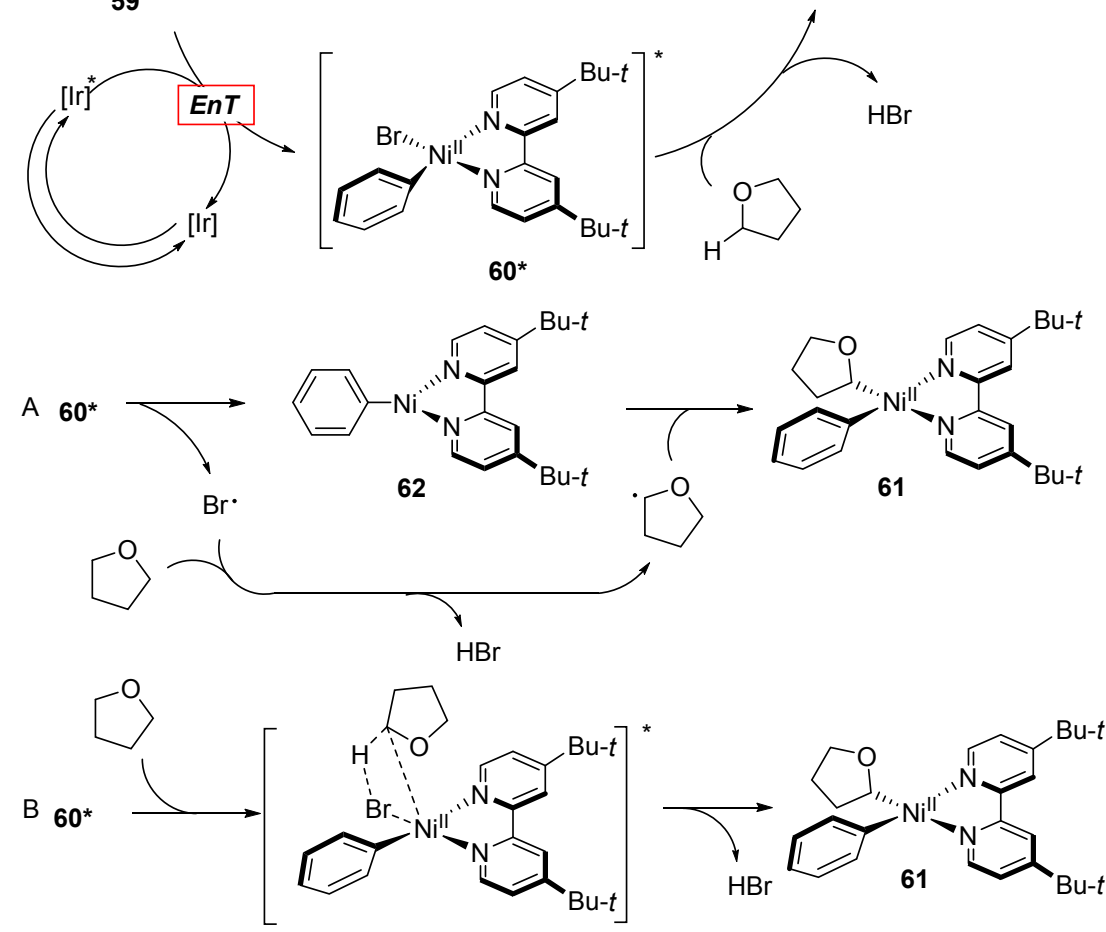

图式 11 碳-氢键芳基化

Scheme 11 Arylation of $\mathrm{C}-\mathrm{H}$ bond

整个催化循环.

当然, 过渡金属镍盐在反应体系中也可以作为路易 斯酸从而促进反应的发生. 2017 年, 肖文精课题组 ${ }^{[70]}$ 研 究了在可见光作用下 $\beta$-酩酯 67 的非对称氧化反应, 得 到了一系列 $\alpha$-差基- $\beta$-二羰基化合物 68 (Eq. 10). 作者将 具有可见光吸收的噻吨酮与手性配体进行有机结合开 发了一种新型的可见光催化剂, 该催化剂具有可见光吸 收与手性配位的双重作用, 为可见光条件下的手性合成 提供了一种新的思路.
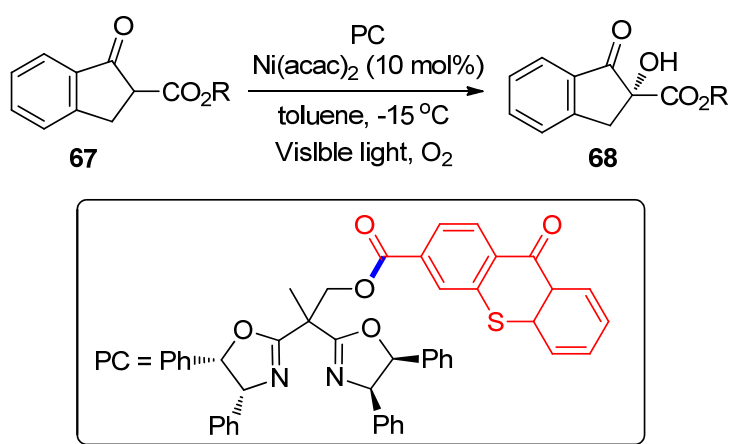

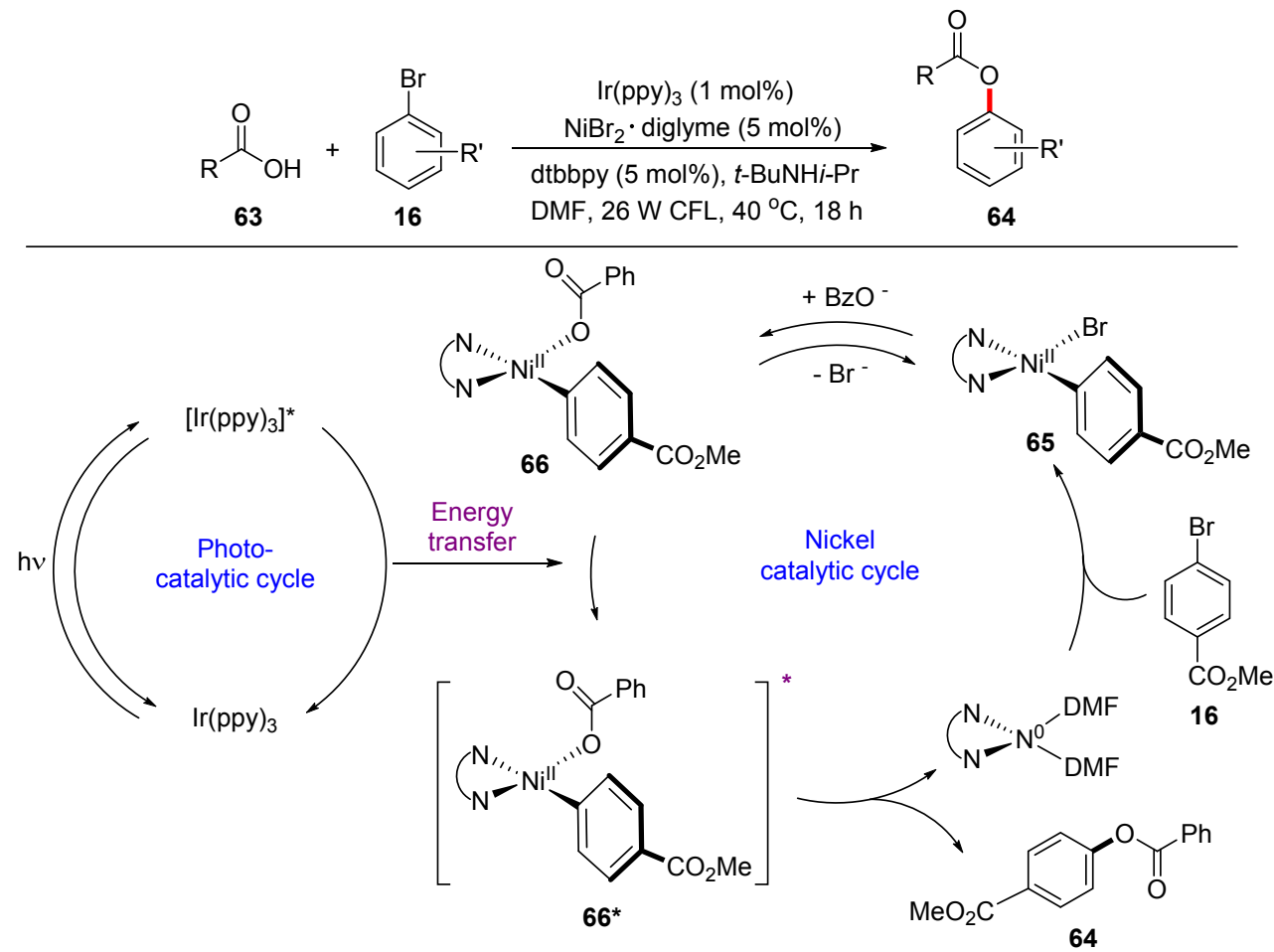

图式 12 羧酸与芳卤的偶联反应

Scheme 12 Coupling of carboxylic acids with aryl halides

\section{3 总结与展望}

综上所述, 镍与可见光协同催化体系为构建新型的 碳一碳键或碳一杂键提供了一种新的方法, 拓宽了清洁的 光能以及过渡金属催化在有机合成中的应用范围. 而 且, 双催化体系反应条件温和、清洁高效, 符合 “绿色 化学” 发展的要求. 然而, 目前协同催化体系还存在诸 多问题，如亲电试剂不够环保、底物需要预官能团化、 可见光催化剂不够廉价等. 此外基于能量转移方式的双 催化体系研究还不够深入. 随着广大科研工作者对双催 化机理的深入研究及新型廉价可见光催化剂的开发, 镍 与可见光双催化体系将在医药、生物、天然产物及全合 成等领域得到广泛应用, 甚至有望将其推广至工业化生 产中.

\section{References}

[1] Zou, Z.; Ye, J.; Sayama, K.; Arakawa, H. Nature 2001, 414, 625.

[2] Nicewicz, D. A.; MacMillan, D. W. C. Science 2008, 322, 77.

[3] Narayanam, J. M. R.; Stephenson, C. R. J. Chem. Soc. Rev. 2011, $40,102$.

[4] Ischay, M. A.; Anzovino, M. E.; Du, J.; Yoon, T. P. J. Am. Chem. Soc. 2008, 130, 12886.

[5] Narayanam, J. M. R.; Tucker, J. W.; Stephenson, C. R. J. J. Am. Chem. Soc. 2009, 131, 8756

[6] Schultz, D. M.; Yoon, T. P. Science 2014, 343, 1239136.

[7] Prier, C. K.; Rankic, D. A.; Macmillan, D. W. C. Chem. Rev. 2013 , 113, 5322.

[8] Dai, X.; Xu, X.; Li, X. Chin. J. Org. Chem. 2013, 33, 2046 (in Chinese).
(戴小军, 许孝良, 李小年, 有机化学, 2013, 33, 2046.)

[9] Guan, B.; Xu, X.; Wang, H.; Li, X. Chin. J. Org. Chem. 2016, 36, 1564 (in Chinese).

(关保川, 许孝良, 王红, 李小年, 有机化学, 2016, 36, 1564.)

[10] Liu, W.; Zheng, X.; Zeng, J.; Cheng, P. Chin. J. Org. Chem. 2017, 37,1 (in Chinese).

(刘薇, 郑昕宇, 曾建国, 程辟, 有机化学, 2017, 37, 1.)

[11] Cheng, X.; Hu, X.; Lu, Z. Chin. J. Org. Chem. 2017, 37, 251 (in Chinese).

(程骁恺, 胡新根, 陆展, 有机化学, 2017, 37, 251.)

[12] Tan, F.; Xiao, W. Acta Chim. Sinica 2015, 73, 85 (in Chinese). (谭芬, 肖文精, 化学学报, 2015, 73, 85.)

[13] Ding, K.; Xiao, W.; Wu, L. Acta Chim. Sinica 2017, 75, 5 (in Chinese). (丁奎岭, 肖文精, 吴骊珠, 化学学报, 2017, 75, 5.)

[14] Pei, P.; Zhang, F.; Yi, H.; Lei, A. Acta Chim. Sinica 2017, 75, 15 (in Chinese).

(裴朋昆, 张凡，易红，雷爱文，化学学报, 2017, 75, 15.)

[15] Wang, D.; Zhang, L.; Luo, S. Acta Chim. Sinica 2017, 75, 22 (in Chinese).

(王德红, 张龙, 罗三中, 化学学报, 2017, 75, 22.)

[16] Zhong, J.; Meng, Q.; Chen, B.; Tung, C.; Wu, L. Acta Chim. Sinica 2017, 75, 34 (in Chinese).

(钟建基, 孟庆元，陈涁，佟振合，吴骊珠，化学学报，2017，75, 34.)

[17] Zhang, J. Chen, Y. Acta Chim. Sinica 2017, 75, 41 (in Chinese). (张晶, 陈以昀, 化学学报, 2017, 75, 41.)

[18] Roh, G.; Iqbal, N. Cho, E. Chin. J. Chem. 2016, 34, 459.

[19] Zuo, Z.; Ahneman, D. T.; Chu, L.; Terrett, J. A.; Doyle, A. G.; MacMillan, D. W. C. Science 2014, 345, 437.

[20] Tellis, J.; Kelly, C.; Primer, D.; Jouffroy, M.; Patel, N.; Molander, G. A. Acc. Chem. Res. 2016, 49, 1429.

[21] Gui, Y.; Sun, L.; Lu, Z.; Yu, D. Org. Chem. Front. 2016, 3, 522.

[22] Zuo, Z.; MacMillan, D. W. C. J. Am. Chem. Soc. 2014, 136, 5257.

[23] Johnston, C. P.; Smith, R. T.; Allmendinger, S.; MacMillan, D. W. C. Nature 2016, 536, 322 .

[24] Zuo, Z.; Cong, H.; Li, W.; Choi, J.; Fu, G. C.; MacMillan, D. W. C. 
J. Am. Chem. Soc. 2016, 138, 1832.

[25] Le, C.; MacMillan, D. W. C. J. Am. Chem. Soc. 2015, 137, 11938.

[26] Chu, L.; Lipshultz, J. M.; MacMillan, D. W. C. Angew. Chem., Int. Ed. 2015, 54, 7929.

[27] Zhang, X.; MacMillan, D. W. C. J. Am. Chem. Soc. 2016, 138, 13862.

[28] Gu, L.; Jin, C.; Liu, J.; Zhang, H.; Yuan, M.; Li, G. Green Chem. 2015, 18, 1201 .

[29] Oderinde, M. S.; Varela-Alvarez, A.; Aquila, B.; Robbins, D. W.; Johannes, J. W. J. Org. Chem. 2015, 80, 7642.

[30] Feng, Q.; Tong, R. J. Am. Chem. Soc. 2017, 139, 6177.

[31] Luo, J.; Zhang, J. ACS Catal. 2016, 6, 873.

[32] Huang, H.; Li, X.; Yu, C.; Zhang, Y.; Mariano, P. S.; Wang, W. Angew. Chem., Int. Ed. 2017, 56, 1500 .

[33] McTiernan, C. D.; Leblanc, X.; Scaiano, J. C. ACS Catal. 2017, 7, 2171.

[34] Tellis, J. C.; Primer, D. N.; Molander, G. A. Science 2014, 345, 433.

[35] Khatib, M. E.; Serafim, R. A. M.; Molander, G. A. Angew. Chem., Int. Ed. 2016, 55, 254.

[36] Gutierrez, O.; Tellis, J. C.; Primer, D. N.; Molander, G. A.; Kozlowski, M. C. J. Am. Chem. Soc. 2015, 137, 4896.

[37] Gutierrez-Bonet, A.; Tellis, J. C. Matsui, J. K.; Vara, B. A.; Molander, G. A. ACS Catal. 2016, 6, 8004.

[38] Tellis, J. C.; Amanu, J.; Molander, G. A. Org. Lett. 2016, 18, 2994.

[39] Ryu, D.; Primer, D. N.; Tellis, J. C.; Molander, G. A. Chem. Eur. J. 2016, 22, 120 .

[40] Yamashita, Y.; Tellis, J. C.; Molander, G. A. Proc. Natl. Acad. Sci. U. S. A. 2015, 112, 12026

[41] Amani, J.; Molander, G. A. J. Org. Chem. 2017, 82, 1856.

[42] Amani, J.; Alam, R.; Badir, S.; Molander, G. A. Org. Lett. 2017, 19, 2426.

[43] Karakaya, I.; Primer, D. N.; Molander, G. A. Org. Lett. 2015, 17, 3294.

[44] Karimi-Nami, R.; Tellis, J. C.; Molander, G. A. Org. Lett. 2016, 18, 2572

[45] Matsui, J. K.; Molander, G. A. Org. Lett. 2017, 19, 436.

[46] Vara, B. A.; Patel, N. R.; Molander, G. A. ACS Catal. 2017, 7, 3955.

[47] Stache, E. E.; Rovis, T.; Doyle, A. G. Angew. Chem., Int. Ed. 2017, 56,3679 .
[48] Corce, V.; Chamoreau, L.; Derat, E.; Coddard, J.; Ollivier, C.; Fensterbank, L. Angew. Chem., Int. Ed. 2015, 54, 11414.

[49] Jouffroy, M.; Primer, D. N.; Molander, G. A. J. Am. Chem. Soc. 2016, 138, 475.

[50] Patel, N. R.; Kelly, C. B.; Jouffroy, M.; Molander, G. A. Org. Lett. 2016, 18, 764 .

[51] Leveque, C.; Corce, V.; Chenneberg, L.; Ollivier, C.; Fensterbank. Eur. J. Org. Chem. 2017, 2017, 2118.

[52] Jouffroy, M.; Davies, G. H.; Molander, G. A. Org. Lett. 2016, 18 , 1606.

[53] Patel, N. R.; Molander, G. A. J. Org. Chem. 2016, 81, 7271.

[54] Vara, B. A.; Jouffroy, M.; Molander, G. A. Chem. Sci. 2017, 8, 530.

[55] Jouffroy, M.; Kelly, C. B.; Molander, G. A. Org. Lett. 2016, 18, 876.

[56] Gutiérrez-Bonet, Á.; Tellis, J. C.; Matsui, J. K.; Vara, B. A.; Molander, G. A. ACS Catal. 2016, 6, 8004

[57] Duan, Z.; Li, W.; Lei, A. Org. Lett. 2016, 18, 4012.

[58] Paul, A.; Smith, M.; Vannucci. J. Org. Chem. 2017, 82, 1996.

[59] Joe, C. L.; Doyle, A. G. Angew. Chem., Int. Ed. 2016, 55, 4040.

[60] Shields, B. J.; Doyle, A. G. J. Am. Chem. Soc. 2016, 138, 12719

[61] Shaw, M. H.; Shurtleff, V. W.; Terrett, J. A.; Cuthbertson, J .D.; MacMillan, D. W. C. Science 2016, 352, 1304.

[62] Gui, Y. Y.; Liao, L. L.; Sun, L.; Zhang, Z.; Ye, J. H.; Shen, G.; Lu, Z. P.; Zhou, W. J.; Yu, D. G. Chem. Commun. 2017, 53, 1192.

[63] Oderinde, M. S.; Frenette, M.; Robbins, D. W.; Aquila, B.; Johannes, J. W. J. Am. Chem. Soc. 2016, 138, 1760.

[64] Xuan, J.; Zeng, T. T.; Chen, J. R.; Lu, L. Q.; Xiao, W. J. Chem. Eur. J. 2015, 21, 4962.

[65] Terrett, J. A.; Cuthbertson, J. D.; Shurtleff, V. W.; MacMillan, D. W. C. Nature 2015, 524, 330 .

[66] Tasker, S. Z.; Jamison, T. F. J. Am. Chem. Soc. 2015, 137, 9531.

[67] Corcoran, E. B.; Piront, M. T.; Lin, S.; Dreher, S. D.; DiRocco, D. A.; Davies, I. W.; Buchwald, S. L.; MacMillan, D. W. C. Science 2016, 353, 279.

[68] Heitz, D. R.; Tellis, J. C.; Molander, G. A. J. Am. Chem. Soc. 2016, $138,12715$.

[69] Welin, E. R.; Le, C.; Arias-Rotondo, D. M.; McCusker, J. K., MacMillan, D. W. C. Science 2017, 355, 380.

[70] Ding, W.; Lu, L.; Zhou, Q.; Wei, Y.; Chen, J.; Xiao, W. J. Am. Chem. Soc. 2017, 139, 63.

(Cheng, F.) 